\title{
FOXM1-mediated downregulation of UPA and MMP9 by 3,3'-diindolylmethane inhibits migration and invasion of human colorectal cancer cells
}

\author{
HUA JIN ${ }^{1}$, XIU JUAN LI ${ }^{1}$, MAN HEE PARK $^{2}$ and SOO MI KIM ${ }^{1}$ \\ ${ }^{1}$ Department of Physiology, Institute for Medical Sciences, Chonbuk National University Medical School, Jeonju; \\ ${ }^{2}$ Catholic University of Pusan, Busan, Republic of Korea
}

Received February 27, 2015; Accepted April 16, 2015

DOI: $10.3892 /$ or.2015.3938

\begin{abstract}
Although 3,3'-diindolylmethane (DIM) has been suggested to reduce the risk of colorectal cancer, the underlying biological mechanism is not clearly understood. In the present study, we investigated the effect of DIM on the migratory and invasive activities of the human colorectal cancer cell lines DLD-1 and HCT116. DIM significantly inhibited the migration and invasion of colorectal cancer cells as assessed by wound healing and Matrigel invasion assays. The migratory ability of the DLD-1 and HCT116 cells was significantly reduced by DIM at 24 and $48 \mathrm{~h}$. DIM also significantly inhibited the invasion rate of the DLD-1 and HCT116 cells in a dose-dependent manner. The mRNA expression levels of urokinase type plasminogen activator (uPA) and matrix metalloprotease 9 (MMP9) were significantly attenuated, whereas expression of E-cadherin mRNA was significantly enhanced, following DIM treatment. DIM also decreased the protein levels of uPA and MMP9, yet significantly increased E-cadherin protein expression. In addition, DIM significantly reduced the mRNA and protein levels of FOXM1 in the DLD-1 and HCT116 cells. Our results suggest that DIM can influence the cell migratory and invasive properties of human colorectal cancer cells and may decrease the invasive capacity of colorectal cancer through downregulation of uPA and MMP9 mediated by suppression of the transcription factor FOXM1.
\end{abstract}

\section{Introduction}

Colorectal cancer is the third most common cancer worldwide, and its incidence in South Korea has dramatically increased as

Correspondence to: Professor Soo Mi Kim, Department of Physiology, Institute for Medical Sciences, Chonbuk National University Medical School, Gungiro 20, Deokjin-Gu, Jeonju 561-180, Republic of Korea

E-mail: soomikim@jbnu.ac.kr

Key words: DIM, invasion, metastasis, uPA, MMP9, FOXM1, colorectal cancer a result of changes in the economy and lifestyle (1). Although genetic predisposition is an important contributing factor for the occurrence of colorectal cancer, the main mechanisms underlying the pathogenesis of colorectal cancer remain largely unclear. Previous studies suggest that diet plays a significant role in colorectal cancer development and progression $(2,3)$. Moreover, cellular migration and invasion are important features of colorectal cancer progression, and therefore interception of the migration and invasion of colorectal cancer cells could be a potential therapeutic target. Despite improvements in conventional therapies for colorectal cancer, the quality of life of patients with colorectal cancer remains poor, and new therapeutic targets or preventive tools for colorectal cancer are therefore urgently needed.

The cancer preventive role of 3,3'-diindolylmethane (DIM) in several types of cancer cells has been highlighted, and several studies have proposed DIM as a potent natural dietary compound that reduces colorectal cancer risk and performs several antitumor activities (4-11). These functions include inhibition of colorectal cancer cell proliferation by suppression of YAP through an Akt-dependent process, alteration of cell cycle progression, and activation of caspase- 8 to induce apoptosis $(6,10,11)$. Movement of cells in the extracellular matrix (ECM) and their adhesion to the ECM are critical processes in the invasion of metastatic colorectal cancer cells. Despite extensive efforts to understand the mechanism underlying adhesion to the ECM during colorectal cancer metastasis, the effects of DIM on the adhesion and migratory properties of colorectal cancer cells have not been elucidated. To clarify the effect of DIM on the metastatic functions of colorectal cancer, we investigated its effect on migration and invasion of cultured colorectal cancer cells. In the present study, we showed that DIM significantly suppressed the cell migratory and invasive properties of colorectal cancer cells and that these effects may be in part mediated through inactivation of FOXM1 and the resultant downregulation of urokinase type plasminogen activator (uPA) and matrix metalloprotease 9 (MMP9).

\section{Materials and methods}

Materials. Antibodies specific for E-cadherin, uPA, FOXM1 and GAPDH were purchased from Santa Cruz Biotechnology 
Inc. (Santa Cruz, CA, USA), and the antibody against MMP9 was purchased from R\&D Systems, Inc. (Minneapolis, MN, USA). DIM was purchased from LKT Laboratories, Inc. (St. Paul, MN, USA).

Cell culture. The DLD-1 and HCT116 cell lines were obtained from the University of Texas M.D. Anderson Cancer Center (Houston, TX, USA). RPMI-1640 medium and Dulbecco's modified Eagle's medium (DMEM)/F12 medium (both from Gibco, Grand Island, NY, USA) were used for cell culture. Cells were grown in RPMI-1640 (DLD-1) or DMEM/F12 (HCT116) supplemented with $10 \%$ fetal bovine serum (FBS; Gibco), $100 \mathrm{mg} / \mathrm{ml}$ streptomycin and $100 \mathrm{IU} / \mathrm{ml}$ penicillin in a $5 \% \mathrm{CO}_{2}$ humidified atmosphere at $37^{\circ} \mathrm{C}$. The DLD-1 and HCT116 cells were treated with various concentrations of DIM in FBS-free medium.

Wound healing assay. To detect the effect of DIM on the migration of the HCT116 and DLD-1 colorectal cancer cells, we performed a wound healing assay as previously described (12). Control and DIM-treated colorectal cancer cells were grown to confluency, and a wound was made through the monolayer using a 200- $\mu 1$ pipette tip. Accurate measurements of the wounds were taken during the time course to calculate the migration rate according to the equation: Percentage of wound healing $=[($ wound length at $0 \mathrm{~h})-($ wound length at 24 or $48 \mathrm{~h})] /$ (wound length at $0 \mathrm{~h}$ ) $\mathrm{x} 100$.

Matrigel invasion assay. BD BioCoat ${ }^{\mathrm{TM}}$ Matrigel $^{\mathrm{TM}}$ Invasion Chambers (BD Biosciences, San Jose, CA, USA) were used for the in vitro cell invasion assay according to the manufacturer's protocol. Briefly, the Matrigel-coated chambers were rehydrated in a humidified tissue culture incubator at $37^{\circ} \mathrm{C}$ in a $5 \% \mathrm{CO}_{2}$ atmosphere. Cells $\left(2.5 \times 10^{4}\right)$ were suspended in $500 \mu \mathrm{l}$ medium in each Matrigel-coated Transwell insert and the lower chamber of the Transwell was filled with $500 \mu \mathrm{l}$ of medium. After incubation, the cultures were washed and stained with a Diff-Quik kit (Sysmex Corp., Kobe, Japan). Cells on the upper side of the insert membrane were removed and cells that migrated to the lower side of the membrane were counted on an inverted microscope (magnification, x100). Five fields were randomly selected, and the invasion rates were calculated as previously described (12).

RNA isolation and real-time PCR. Total RNA was isolated from the DLD-1 and HCT116 cells before and after DIM $(100 \mu \mathrm{M})$ treatment. Reverse transcription was carried out with a PrimeScript ${ }^{\mathrm{TM}}$ RT reagent kit (Takara Bio Inc., Otsu, Shiga, Japan) according to the manufacturer's protocol. Quantitative real-time PCR was performed using SYBR Premix Ex Taq (Takara Bio Inc.) in an ABI Prism 7900 Sequence Detection System (Applied Biosystems, Foster City, CA, USA). The PCR program was initiated at $95^{\circ} \mathrm{C}$ for $30 \mathrm{sec}$ followed by 40 cycles of $95^{\circ} \mathrm{C}$ for $15 \mathrm{sec}$ and $60^{\circ} \mathrm{C}$ for $1 \mathrm{~min}$. The results were normalized to those for GAPDH and were calculated from threshold cycle numbers. Primer sequences were as follows: E-cadherin sense, 5'-GGATTGCAAATTC CTGCCATTC-3' and antisense, 5'-AACGTTGTCCCGGGTG TCA-3'; uPA sense, 5'-AGAATTCACCACCATCGAGA-3' and antisense, 5'-ATCAGCTTCACAACAGTCAT-3'; MMP9 sense, 5'-GACCTCAAGTGGCACCACCA-3' and antisense, 5'-GTGGTACTGCACCAGGGCAA-3; FOXM1 sense, 5'-AC GTCCCCAAGCCAGGCTC-3 and antisense, 5'-CTACTG TAGCTCAGGAATAA-3'; GAPDH sense, 5'-GTCTCCTC TGACTTCAACAGCG-3' and antisense, 5'-ACCACCCTGTT GCTGTAGCCAA-3'.

Western blot analysis. Colorectal cancer DLD-1 and HCT116 cells were treated with DIM at the indicated concentrations for $48 \mathrm{~h}$. Cell lysates were prepared by suspending the cells in lysis buffer (Intron Biotechnology, Seoul, Korea), and western blot analysis was performed as previously described $(6,13)$. Briefly, cell extractions were incubated on ice for $20 \mathrm{~min}$ and centrifuged at $13,000 \mathrm{xg}$ for $5 \mathrm{~min}$ at $4^{\circ} \mathrm{C}(6)$. The protein concentration was determined using a BSA protein assay kit (Pierce, Rockford, IL, USA). Whole lysate was resolved on an SDS-PAGE gel, and transferred to a PVDF membrane (BioRad, Hercules, CA, USA) (6).

Statistical analysis. The statistical significance of differences between groups was tested by one-way ANOVA and then later compared among groups with an unpaired Student's t-test. The experimental data are presented as the means \pm SEM. A p-value $<0.05$ was considered to indicate a statistically significant result. All experiments were repeated more than three times.

\section{Results}

DIM inhibits the migration of colorectal cancer cells. A wound healing assay was performed to investigate the effect of DIM on colorectal cancer cell migration. This assay tested the effect of DIM on the migration of the DLD-1 and HCT116 cells based on the ability of cells to interact with extracellular matrix in the presence of DIM. In the presence of $20 \mu \mathrm{M}$ DIM, the migratory ability of the DLD-1 and HCT116 cells maintained in 5\% FBS was significantly reduced at 24 and $48 \mathrm{~h}$ (Fig. 1A and B). Treatment of the DLD-1 and HCT116 cells with $50 \mu \mathrm{M}$ DIM in the presence of $10 \%$ FBS had an even greater antimigratory effect at 24 and 48 h (Fig. 2). These results indicate that DIM has an antimigratory effect on colorectal cancer cells.

DIM inhibits the invasion of colorectal cancer cells. We further investigated the effect of DIM on colorectal cancer cell invasion using a Matrigel invasion assay. We found that DIM significantly inhibited the invasion of the DLD-1 and HCT116 cells in a dose-dependent manner; $20 \mu \mathrm{M}$ DIM significantly suppressed the invasion rates by 20 and $40 \%$ in the DLD- 1 and HCT116 cells, respectively, whereas $50 \mu \mathrm{M}$ DIM suppressed the invasion rates of both cell lines by $70 \%$ (Fig. 3). These data suggest that DIM significantly inhibits the migration and invasion rates of colorectal cancer cells.

Effect of DIM on the expression of migration-related $m R N A s$ and proteins in colorectal cancer cells. To further study the effect of DIM on the migration and invasion of colorectal cancer cells, we performed RT-PCR and western blot analyses to investigate the underlying molecular events. Loss of E-cadherin expression is used as an indicator of 
A
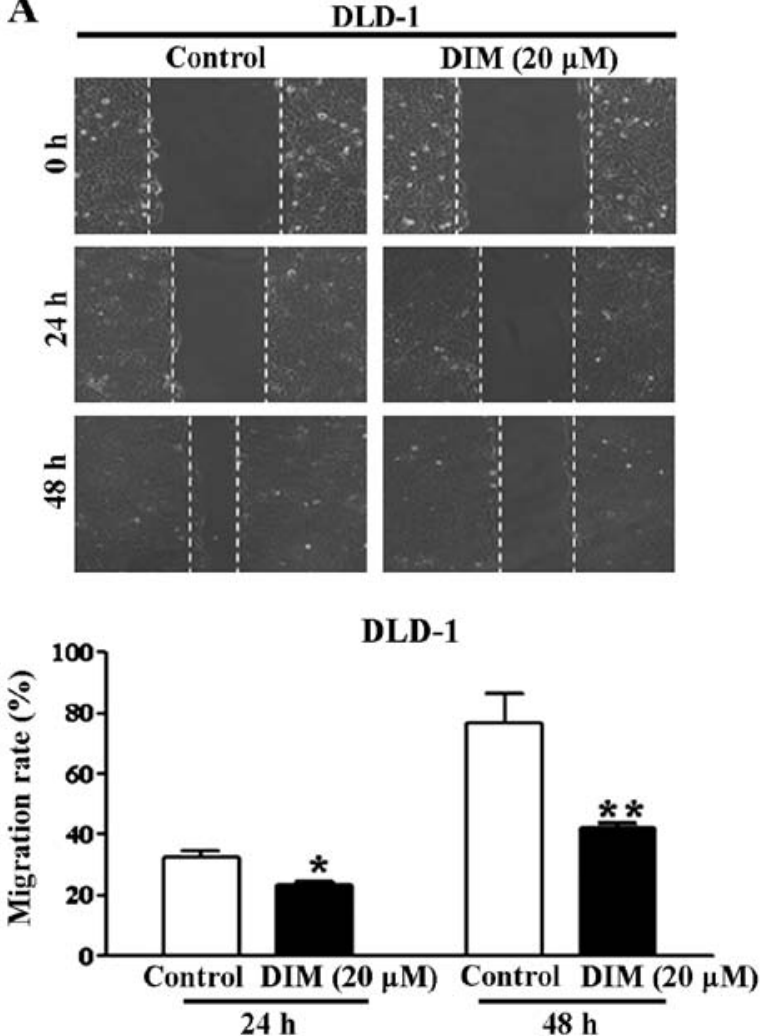

B

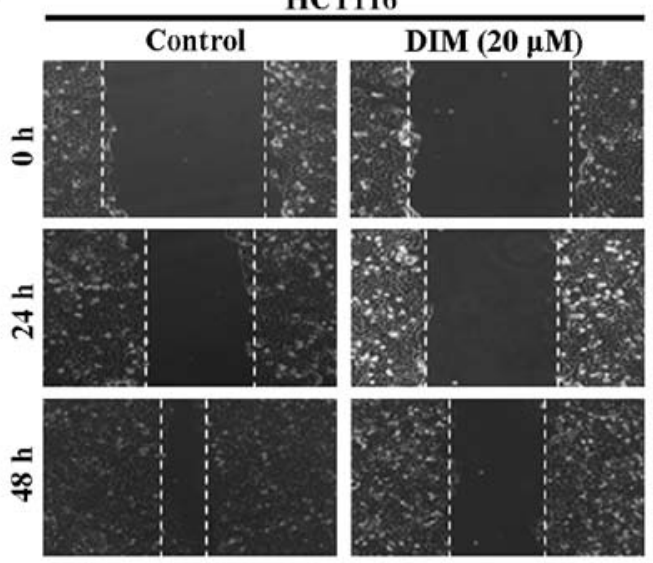

HCT116

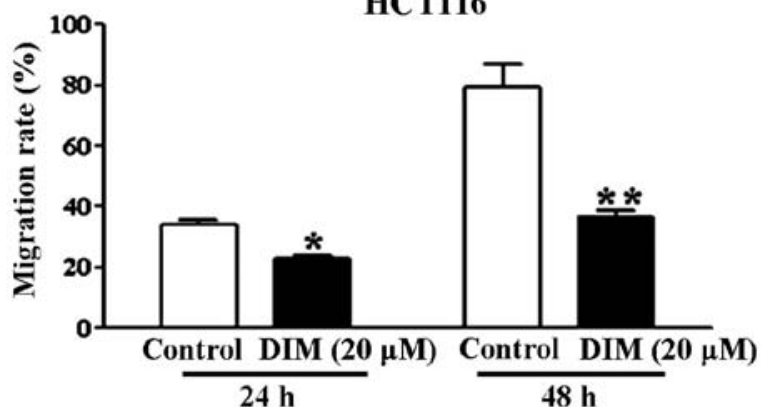

Figure 1. Effect of DIM on the migration rates of the colorectal cancer cells assessed by a wound healing assay. (A) DLD-1 and (B) HCT116 cells were treated with $20 \mu \mathrm{M}$ DIM with 5\% FBS and incubated for 24 and $48 \mathrm{~h}$. Both the DLD-1 and HCT116 cells showed a significant antimigratory effect at 24 and $48 \mathrm{~h}$. " $\mathrm{p}<0.05$ and ${ }^{* *} \mathrm{p}<0.01$ compared to the control. DIM, 3,3'-diindolylmethane; FBS, fetal bovine serum.

A
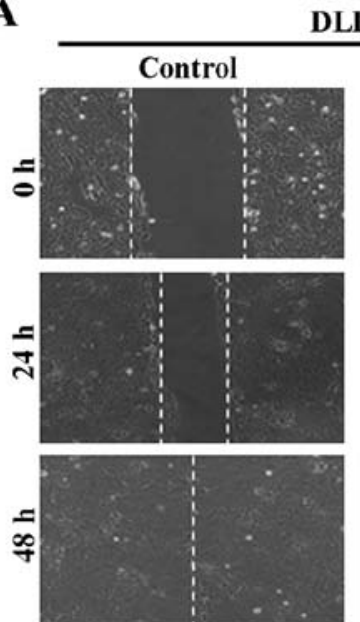

DLD-1

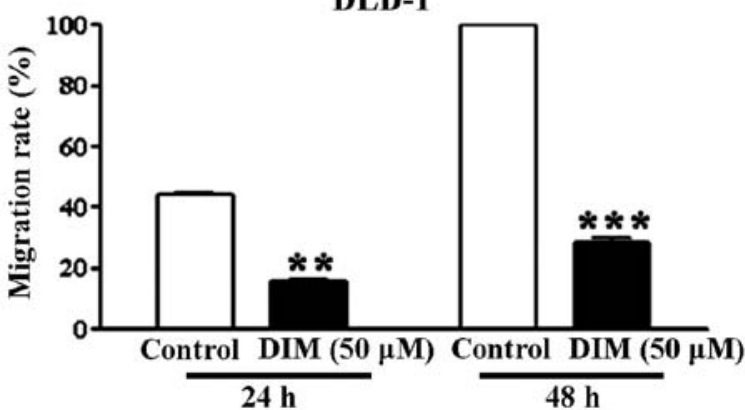

B
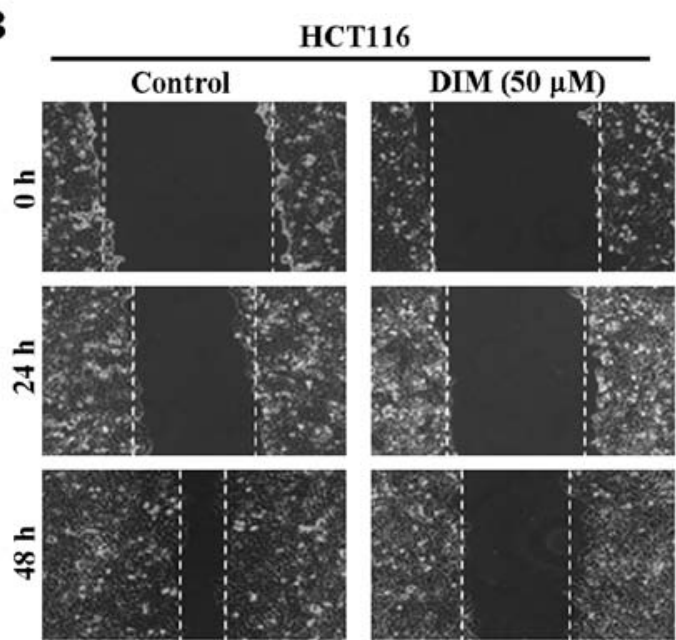

HCT116

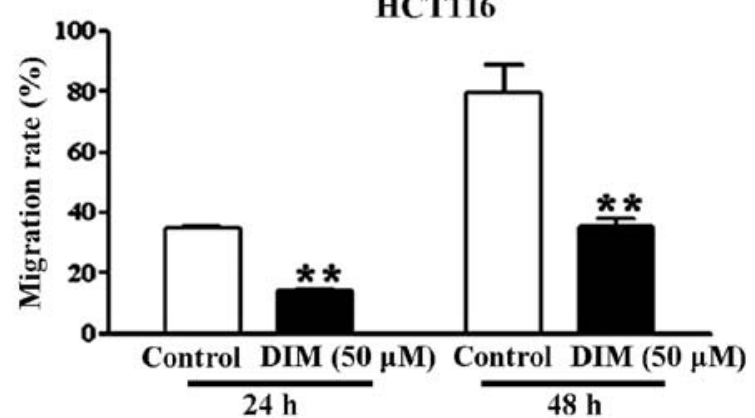

Figure 2. Effect of DIM on the migration rates of colorectal cancer cells by wound healing assay. (A) DLD-1 and (B) HCT116 colon cancer cells were treated with $50 \mu \mathrm{M}$ DIM in the presence of $10 \%$ FBS. Treatment with $50 \mu \mathrm{M}$ DIM showed a significant antimigratory effect at 24 and $48 \mathrm{~h}$ in both cell lines. ${ }^{* *}$ p $<0.01$, **** $\mathrm{p}<0.001$ compared to the control. DIM, 3,3'-diindolylmethane; FBS, fetal bovine serum. 

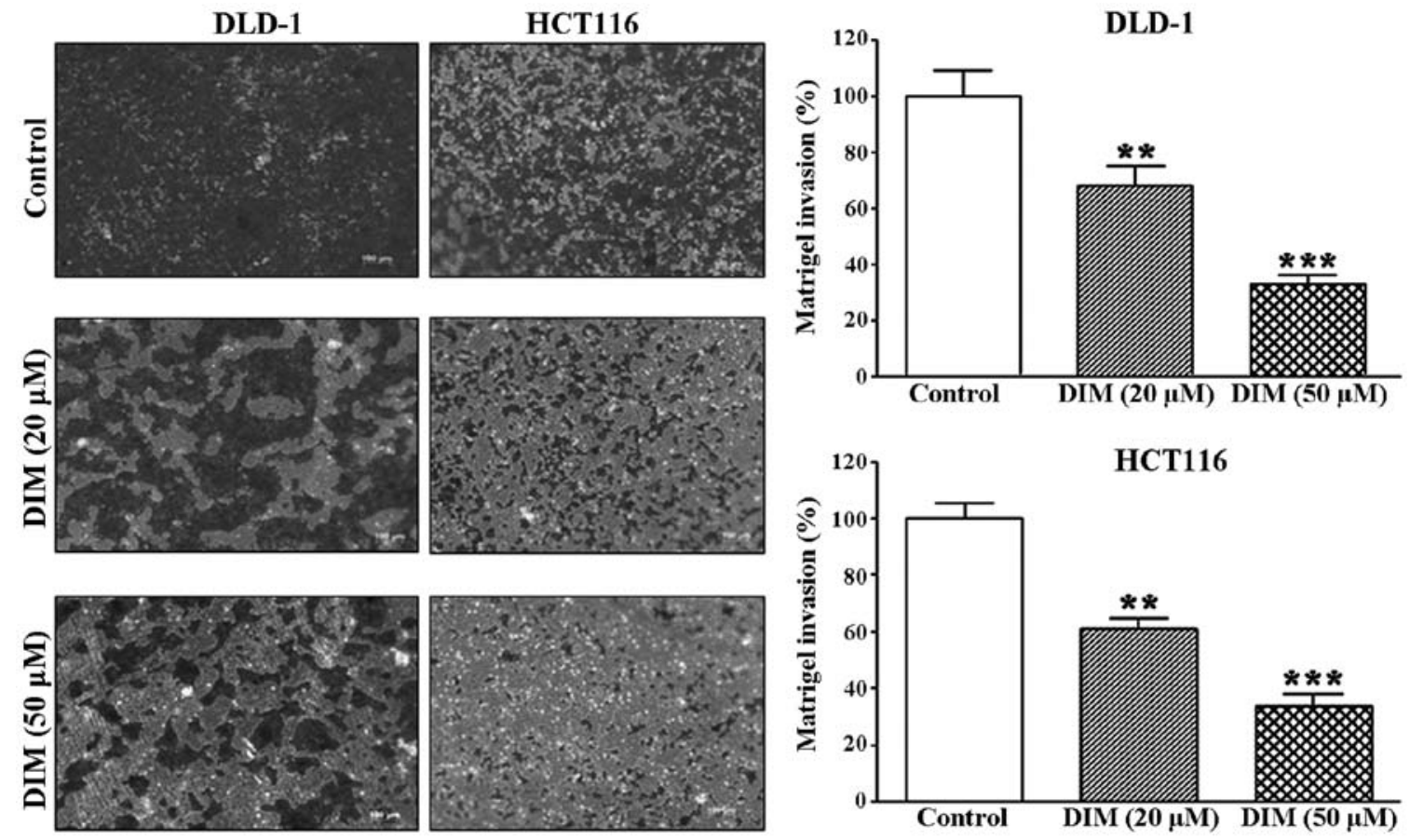

Figure 3. Effect of DIM on the invasion rates of colorectal cancer cells by Matrigel invasion assay. DIM significantly inhibited the invasion rates of the DLD-1 and HCT116 cells at concentrations of 20 and $50 \mu \mathrm{M}$. ${ }^{* *} \mathrm{p}<0.01,{ }^{* * *} \mathrm{p}<0.001$ compared to control. DIM, 3,3'-diindolylmethane.
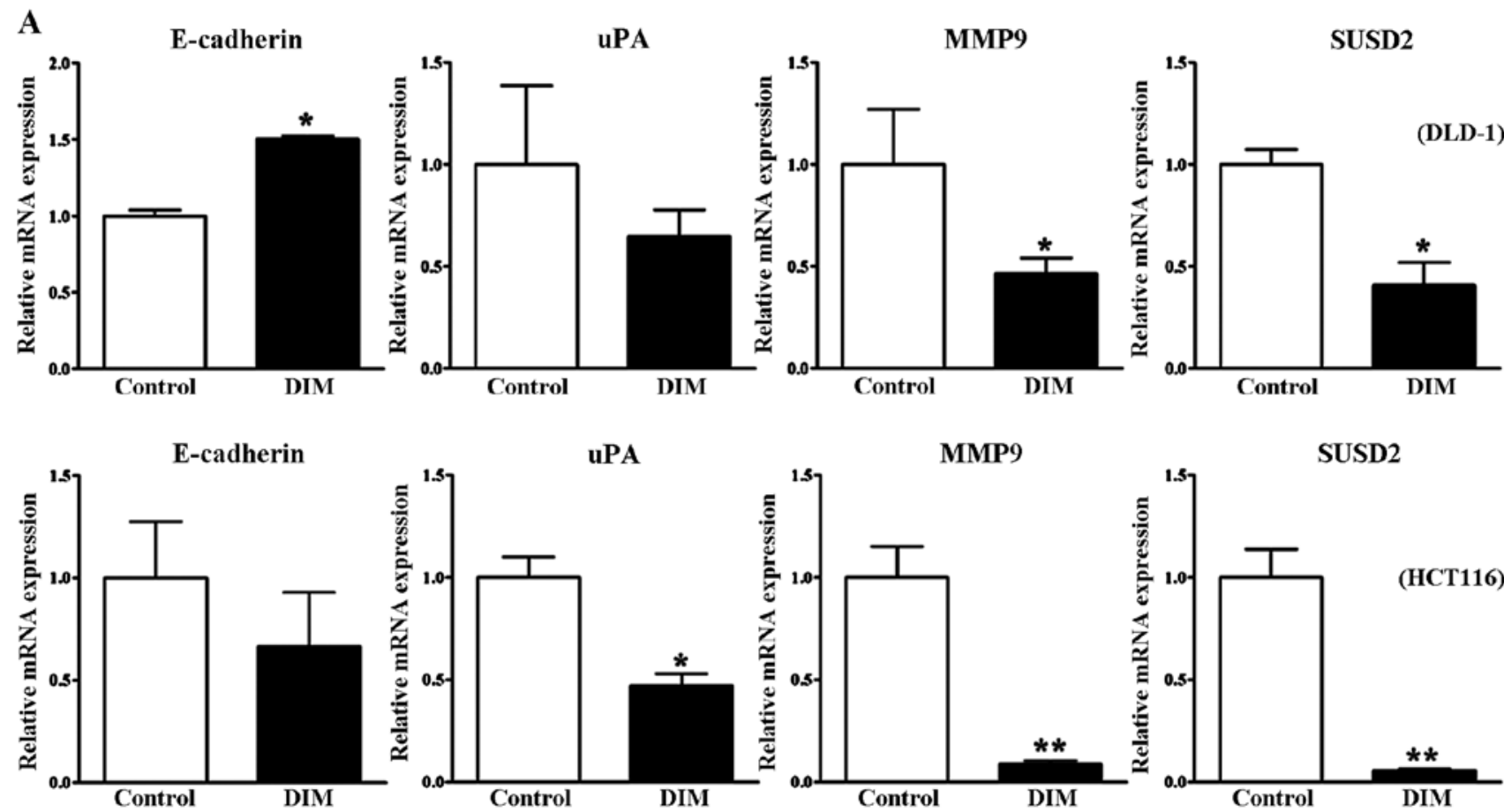

Figure 4. Expression of metastasis marker genes in colorectal cancer cells after DIM treatment. (A) mRNA levels of E-cadherin, uPA, MMP9 and SUSD2 in the DLD-1 and HCT116 cells were measured by real-time PCR after treatment with DIM $(100 \mu \mathrm{M})$ for $48 \mathrm{~h}$. Data are expressed as mean ( \pm SE). Values were normalized to GAPDH. ${ }^{*} \mathrm{p}<0.05,{ }^{* *} \mathrm{p}<0.01$ compared to the control.

invasive epithelial cancers. In the present study, DIM treatment induced a significant increase in the E-cadherin mRNA level in the DLD-1 cells, yet there was no significant change in the HCT 116 cells (Fig. 4A). However, E-cadherin protein levels were significantly increased following DIM treatment in both the DLD-1 and HCT116 cells in a dose-dependent manner (Fig. 4B). Therefore, our data indicated that DIM increased E-cadherin expression and thus suppressed the invasiveness and progression of colon cancer cells. We further found that treatment with $100 \mu \mathrm{M}$ DIM significantly decreased the mRNA levels of genes related to invasion and cancer progression such as uPA, MMP9 and SUSD2 in DLD-1 
B

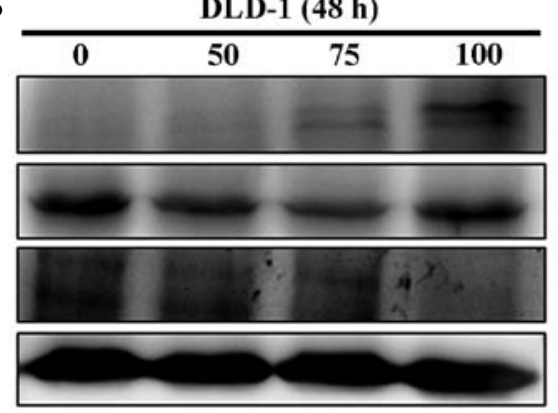

HCT116 (48 h)

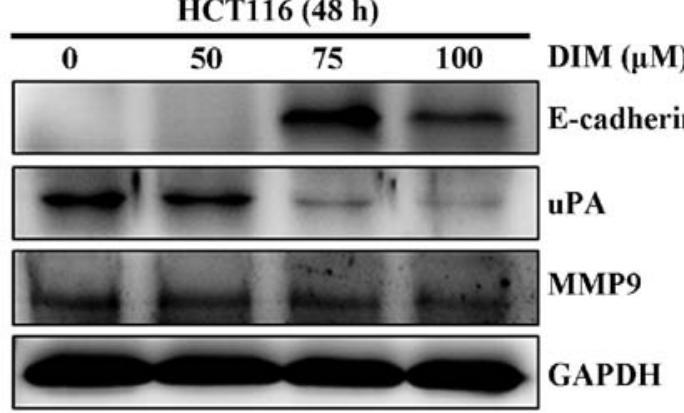

Figure 4. Continued. (B) Western blot analysis of the effect of DIM on E-cadherin, uPA and MMP9 protein expression in the DLD-1 and HCT116 cells. The protein levels of E-catenin, uPA and MMP9 were measured after DIM (0, 50, 75 and $100 \mu \mathrm{M})$ treatment for 48 h. GAPDH was used as an internal control. DIM, 3,3'-diindolylmethane.
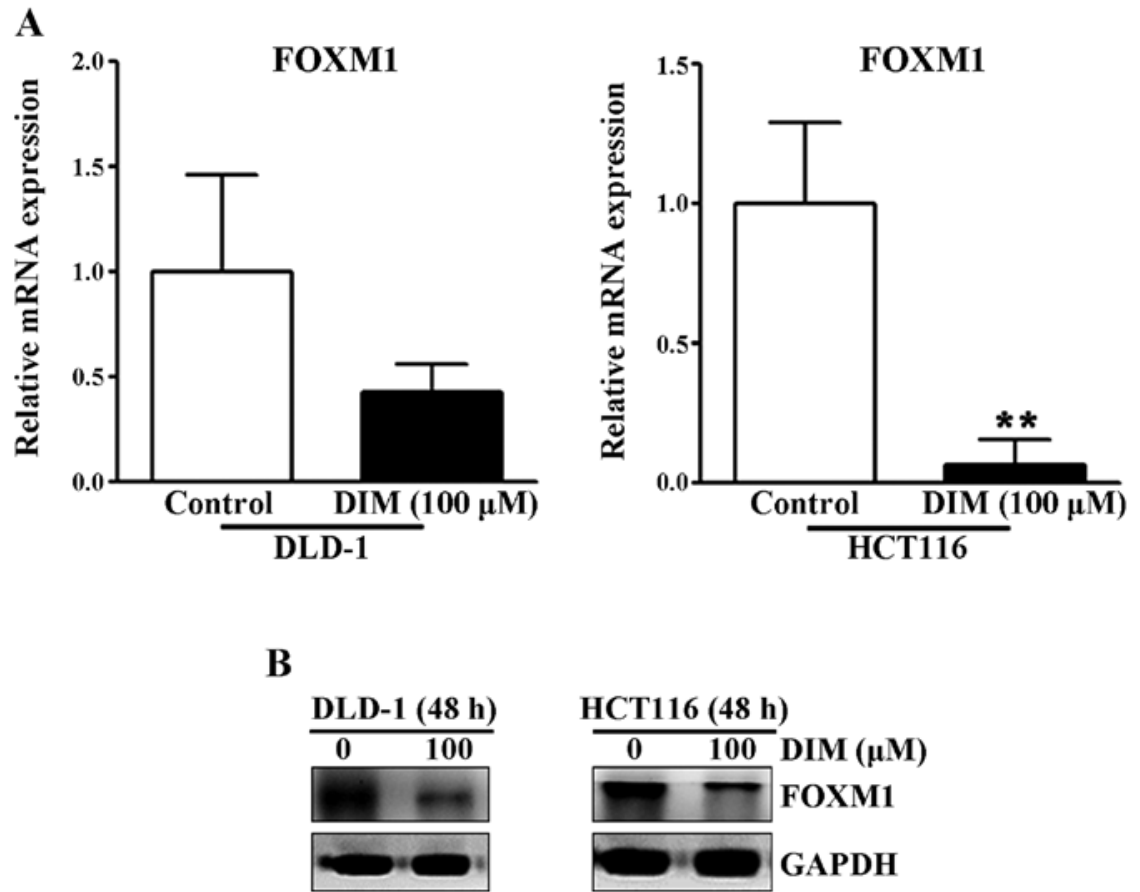

Figure 5. Expression of FOXM1 in colorectal cancer cells after DIM treatment. (A) The mRNA level of FOXM1 in the DLD-1 and HCT116 cells was measured by real-time PCR after treatment with DIM $(100 \mu \mathrm{M})$ for $48 \mathrm{~h}$. Data are expressed as the mean $\left( \pm\right.$ SE). Values were normalized to GAPDH. ${ }^{* *}$ p $<0.01$ compared to the control. (B) Western blot analysis of the effect of DIM on FOXM1 protein expression in the DLD-1 and HCT116 cells. The FOXM1 protein level was measured after DIM $(100 \mu \mathrm{M})$ treatment for $48 \mathrm{~h}$. GAPDH was used as an internal control. DIM, 3,3'-diindolylmethane.

and HCT-116 cells (Fig. 4A). The protein levels of uPA and MMP9 were also downregulated in a dose-dependent manner after DIM treatment (Fig. 4B). These results suggest that DIM inhibits the migration and invasion of colorectal cancer cells by targeting UPA and MMP9.

Effect of DIM on FOXM1 protein and mRNA expression levels in colorectal cancer cells. The transcription factor forkhead box M1 (FOXM1) is an important regulator of cell differentiation and proliferation (14). Since FOXM1 is highly activated in most human cancers and is overexpressed in a number of aggressive human carcinomas (14), we examined whether DIM alters the expression levels of FOXM1 in colorectal cancer cells. As shown in Fig. 5, DIM significantly reduced the mRNA and protein levels of FOXM1 in the DLD-1 and HCT116 cells at $48 \mathrm{~h}$, suggesting that DIM significantly inhibits the migration and invasion rates of colorectal cancer cells by inactivation of FOXM1.

\section{Discussion}

DIM is considered to be a promising natural cancer preventive agent. Although DIM has been proven to impart antitumor effects on numerous cancers both in vitro and in vivo (4-9,11,13,15-19), its antimetastatic effects in colorectal cancer and the underlying mechanism have not been fully elucidated. In the present study, we demonstrated that DIM inhibits the migration and invasion of colorectal cancer cells by inactivation of FOXM1 and subsequent downregulation of uPA and MMP9.

In the present study, we found that there was a significant reduction in cellular migration of colorectal cancer 
cells (DLD-1 and HCT116) following treatment with 20 and $50 \mu \mathrm{M}$ DIM. Treatment with $50 \mu \mathrm{M}$ DIM with $10 \%$ FBS of the colorectal cancer cells resulted in a more pronounced inhibition of migration than treatment with $20 \mu \mathrm{M}$ DIM with $5 \%$ FBS. DIM at concentrations of 20 and $50 \mu \mathrm{M}$ also significantly inhibited the invasion rates of the DLD-1 and HCT116 cells in a Matrigel invasion assay. The inhibition of cancer cell metastatic function by DIM has been reported by many researchers in various types of cancer including prostate, breast, ovarian, thyroid and nasopharyngeal cancers (15-23). A previous study on the antitumor effects and chemopreventive role of DIM in colorectal cancer proposed that DIM inhibited colorectal cancer cells by inactivation of YAP and induction of G1 and G2 cell cycle arrest $(6,8)$. However, the effects of DIM on invasion and metastasis in colorectal cancer cells have not previously been described, and this is the first study to show attenuation of the adhesion and migratory properties of colorectal cancer cells by DIM.

As our data showed that DIM regulated colorectal cancer cell invasion and metastasis, we further investigated whether DIM altered the expression levels of metastasis marker proteins in colorectal cancer cells. Indeed, DIM significantly induced expression of E-cadherin, an indicator protein of invasive function in epithelial cancer cells, in both the DLD-1 and HCT116 cells. Our findings suggest that induction of E-cadherin expression by DIM treatment represents loss of epithelial invasive function in colorectal cancer cells. We also found that DIM decreased the protein levels of UPA and MMP9 and significantly downregulated mRNA levels of UPA, MMP9, and SUSD2 in the DLD-1 and HCT116 cells. Our results are consistent with those of previous studies in other cancer cells. For example, inhibition of invasion in prostate cancer by DIM was previously shown to be mediated by MMP9 and UPA, which regulated the bioavailability of vascular endothelial growth factor (18). Downregulation of UPA by DIM has also been reported to contribute to the inhibition of cell growth and migration of breast cancer cells (15). Therefore, our results strongly indicated that inhibition of UPA and MMP9 by DIM attenuates the invasion and metastasis of colorectal cancer cells.

Forkhead box M1 (FOXM1) is a member of the FOX family of transcriptional factors and a cell cycle regulator that is essential for cell cycle progression (24). FOXM1 has been reported to play an important role in the promotion of cancer cell proliferation and to be involved in malignant tumor development in a variety of cancers, including lung, liver, ovarian and breast cancer (24-30). Moreover, overexpression of FOXM1 is associated with tumor invasion and metastasis and predictive of poor prognosis in many cancer types, including ovarian, esophageal, lung, liver and bladder cancer (31-35). Chu et al reported that overexpression of FOXM1 stimulated migration/invasion and is correlated with a poor prognosis of colorectal cancer (36). Activation of FOXM1 increases colorectal cancer progression and metastasis by activation of uPA receptor expression (37). Therefore, it is obvious that abnormal regulation of FOXM1 plays a critical role in tumor development and metastasis of colorectal cancer.

Since elevated expression of FOXM1 has been observed in human colorectal cancer (36,37), we investigated whether DIM altered the expression levels of FOXM1 in colorectal cancer cells. We found that DIM significantly suppressed the mRNA and protein levels of FOXM1 in two different colorectal cancer cells (DLD-1 and HCT116). These observations are in agreement with previous studies demonstrating that DIM effectively downregulated FOXM1 in various breast cancer cell lines (38-40). Downregulation of FOXM1 has been found to inhibit the expression of metastasis factors that are involved in the degradation of the ECM, such as UPA and MMP9, in breast cancer cells (41). In the present study, we found that the inhibition of migration and metastasis by DIM was accompanied by downregulation of FOXM1, uPA and MMP9. Therefore, the antimetastatic effects of DIM in colorectal cancer cells may be associated with inhibition of FOXM1, which in turn may induce downregulation of UPA and MMP9 expression. However, further studies are needed to elucidate how DIM specifically controls the expression of FOXM1 and its target genes.

In conclusion, DIM inhibited the cell migratory and invasive properties of colorectal cancer cells, most likely through downregulation of UPA and MMP9 mediated by suppression of the FOXM1 transcription factor. Our results suggest the potential application of FOXM1 downregulation by DIM as a novel approach for the treatment of aggressive colorectal cancer.

\section{Acknowledgements}

This study was supported by a National Research Foundation of Korea (NRF) grant funded by the Korea Government (MISP) (no. 2008-0062279).

\section{References}

1. Byun JY, Yoon SJ, Oh IH, Kim YA, Seo HY and Lee YH: Economic burden of colorectal cancer in Korea. J Prev Med Pub Health 47: 84-93, 2014.

2. Irrazábal T, Belcheva A, Girardin SE, Martin A and Philpott DJ: The multifaceted role of the intestinal microbiota in colon cancer. Mol Cell 54: 309-320, 2014.

3. Louis P, Hold GL and Flint HJ: The gut microbiota, bacterial metabolites and colorectal cancer. Nat Rev Microbiol 12: 661-672, 2014

4. Kandekar S, Preet R, Kashyap M, Renu Prasad MU, Mohapatra P, Das D, Satapathy SR, Siddharth S, Jain V, Choudhuri M, et al: Structural elaboration of a natural product: Identification of 3,3'-diindolylmethane aminophosphonate and urea derivatives as potent anticancer agents. ChemMedChem 8: 1873-1884, 2013.

5. Li Y, Li X and Guo B: Chemopreventive agent 3,3'-diindolylmethane selectively induces proteasomal degradation of class I histone deacetylases. Cancer Res 70: 646-654, 2010.

6. Li XJ, Leem SH, Park MH and Kim SM: Regulation of YAP through an Akt-dependent process by 3, 3'-diindolylmethane in human colon cancer cells. Int J Oncol 43: 1992-1998, 2013.

7. Park C, Choi YW, Hyun SK, Kwon HJ, Hwang HJ, Kim GY, Choi BT, Kim BW, Choi IW, Moon SK, et al: Induction of G1 arrest and apoptosis by schisandrin C isolated from Schizandra chinensis Baill in human leukemia U937 cells. Int J Mol Med 24: 495-502, 2009.

8. Choi HJ, Lim Y and Park JH: Induction of G1 and G2/M cell cycle arrests by the dietary compound 3,3'-diindolylmethane in HT-29 human colon cancer cells. BMC Gastroenterol 9: 39, 2009.

9. Bhatnagar N, Li X, Chen Y, Zhou X, Garrett SH and Guo B: 3,3'-Diindolylmethane enhances the efficacy of butyrate in colon cancer prevention through down-regulation of survivin. Cancer Prev Res 2: 581-589, 2009.

10. Pappa G, Strathmann J, Löwinger M, Bartsch H and Gerhäuser C: Quantitative combination effects between sulforaphane and 3,3'-diindolylmethane on proliferation of human colon cancer cells in vitro. Carcinogenesis 28: 1471-1477, 2007. 
11. Kim EJ, Park SY, Shin HK, Kwon DY, Surh YJ and Park JH: Activation of caspase-8 contributes to 3,3'-diindolylmethaneinduced apoptosis in colon cancer cells. J Nutr 137: 31-36, 2007.

12. Lee KB, Ye S, Park MH, Park BH, Lee JS and Kim SM: p63-Mediated activation of the $\beta$-catenin/c-Myc signaling pathway stimulates esophageal squamous carcinoma cell invasion and metastasis. Cancer Lett 353: 124-132, 2014.

13. Li XJ, Park ES, Park MH and Kim SM: 3,3'-Diindolylmethane suppresses the growth of gastric cancer cells via activation of the Hippo signaling pathway. Oncol Rep 30: 2419-2426, 2013.

14. Halasi M and Gartel AL: Targeting FOXM1 in cancer. Biochem Pharmacol 85: 644-652, 2013.

15. Ahmad A, Kong D, Wang Z, Sarkar SH, Banerjee S and Sarkar FH: Down-regulation of uPA and uPAR by 3,3'-diindolylmethane contributes to the inhibition of cell growth and migration of breast cancer cells. J Cell Biochem 108: 916-925, 2009.

16. Chang X, Tou JC, Hong C, Kim HA, Riby JE, Firestone GL and Bjeldanes LF: 3,3'-Diindolylmethane inhibits angiogenesis and the growth of transplantable human breast carcinoma in athymic mice. Carcinogenesis 26: 771-778, 2005.

17. Kandala PK and Srivastava SK: Diindolylmethane suppresses ovarian cancer growth and potentiates the effect of cisplatin in tumor mouse model by targeting signal transducer and activator of transcription 3 (STAT3). BMC Med 10: 9, 2012.

18. Kong D, Li Y, Wang Z, Banerjee S and Sarkar FH: Inhibition of angiogenesis and invasion by 3,3'-diindolylmethane is mediated by the nuclear factor-kappaB downstream target genes MMP-9 and UPA that regulated bioavailability of vascular endothelial growth factor in prostate cancer. Cancer Res 67: 3310-3319, 2007.

19. Rahimi M, Huang KL and Tang CK: 3,3'-Diindolylmethane (DIM) inhibits the growth and invasion of drug-resistant human cancer cells expressing EGFR mutants. Cancer Lett 295: 59-68, 2010.

20. Wu T, Chen $\mathrm{C}, \mathrm{Li} \mathrm{F}$, Chen $\mathrm{Z}, \mathrm{Xu} \mathrm{Y}, \mathrm{Xiao} \mathrm{B}$ and Tao Z: 3,3'-Diindolylmethane inhibits the invasion and metastasis of nasopharyngeal carcinoma cells in vitro and in vivo by regulation of epithelial mesenchymal transition. Exp Ther Med 7 : $1635-1638,2014$

21. Ribaux P, Irion $\mathrm{O}$ and Cohen $\mathrm{M}$ : An active product of cruciferous vegetables, 3,3'-diindolylmethane, inhibits invasive properties of extravillous cytotrophoblastic cells. Neuro Endocrinol Lett 33: 133-137, 2012.

22. Rajoria S, Suriano R, George A, Shanmugam A, Schantz SP, Geliebter J and Tiwari RK: Estrogen induced metastatic modulators MMP-2 and MMP-9 are targets of 3,3'-diindolylmethane in thyroid cancer. PLoS One 6: e15879, 2011.

23. Rajoria S, Suriano R, Wilson YL, Schantz SP, Moscatello A, Geliebter J and Tiwari RK: 3,3'-Diindolylmethane inhibits migration and invasion of human cancer cells through combined suppression of ERK and AKT pathways. Oncol Rep 25: 491-497, 2011.

24. Xu N, Jia D, Chen W, Wang H, Liu F, Ge H, Zhu X, Song Y, Zhang X, Zhang D, et al: FoxM1 is associated with poor prognosis of non-small cell lung cancer patients through promoting tumor metastasis. PLoS One 8: e59412, 2013.

25. Kalin TV, Wang IC, Ackerson TJ, Major ML, Detrisac CJ, Kalinichenko VV, Lyubimov A and Costa RH: Increased levels of the FoxM1 transcription factor accelerate development and progression of prostate carcinomas in both TRAMP and LADY transgenic mice. Cancer Res 66: 1712-1720, 2006.

26. Kim IM, Ackerson T, Ramakrishna S, Tretiakova M, Wang IC, Kalin TV, Major ML, Gusarova GA, Yoder HM, Costa RH, et al: The Forkhead Box $\mathrm{m} 1$ transcription factor stimulates the proliferation of tumor cells during development of lung cancer Cancer Res 66: 2153-2161, 2006.
27. Balli D, Zhang Y, Snyder J, Kalinichenko VV and Kalin TV Endothelial cell-specific deletion of transcription factor FoxM1 increases urethane-induced lung carcinogenesis. Cancer Res 71: 40-50, 2011.

28. Calvisi DF, Pinna F, Ladu S, Pellegrino R, Simile MM, Frau M, De Miglio MR, Tomasi ML, Sanna V, Muroni MR, et al: Forkhead box M1B is a determinant of rat susceptibility to hepatocarcinogenesis and sustains ERK activity in human HCC. Gut 58: 679-687, 2009.

29. Chandran UR, Ma C, Dhir R, Bisceglia M, Lyons-Weiler M, Liang W, Michalopoulos G, Becich M and Monzon FA: Gene expression profiles of prostate cancer reveal involvement of multiple molecular pathways in the metastatic process. BMC Cancer 7: 64, 2007.

30. Millour J, Constantinidou D, Stavropoulou AV, Wilson MS, Myatt SS, Kwok JM, Sivanandan K, Coombes RC, Medema RH, Hartman J, et al: FOXM1 is a transcriptional target of ERalpha and has a critical role in breast cancer endocrine sensitivity and resistance. Oncogene 29: 2983-2995, 2010.

31. Wen N, Wang Y, Wen L, Zhao SH, Ai ZH, Wang Y, Wu B, Lu HX, Yang H, Liu WC, et al: Overexpression of FOXM1 predicts poor prognosis and promotes cancer cell proliferation, migration and invasion in epithelial ovarian cancer. J Transl Med 12: 134, 2014.

32. Takata A, Takiguchi S, Okada K, Takahashi T, Kurokawa Y, Yamasaki M, Miyata H, Nakajima K, Mori M and Doki Y: Clinicopathological and prognostic significance of FOXM1 expression in esophageal squamous cell carcinoma. Anticancer Res 34: 2427-2432, 2014.

33. Kong FF, Qu ZQ, Yuan HH, Wang JY, Zhao M, Guo YH, Shi J, Gong XD, Zhu YL, Liu F, et al: Overexpression of FOXM1 is associated with EMT and is a predictor of poor prognosis in non-small cell lung cancer. Oncol Rep 31: 2660-2668, 2014.

34. Xia L, Huang W, Tian D, Chen Z, Zhang L, Li Y, Hu H, Liu J, Chen Z, Tang G, et al: ACP5, a direct transcriptional target of FoxM1, promotes tumor metastasis and indicates poor prognosis in hepatocellular carcinoma. Oncogene 33: 1395-1406, 2014.

35. Liu D, Zhang Z and Kong CZ: High FOXM1 expression was associated with bladder carcinogenesis. Tumour Biol 34: 1131-1138, 2013.

36. Chu XY, Zhu ZM, Chen LB, Wang JH, Su QS, Yang JR, Lin Y, Xue LJ, Liu XB and Mo XB: FOXM1 expression correlates with tumor invasion and a poor prognosis of colorectal cancer. Acta Histochem 114: 755-762, 2012.

37. Li D, Wei P, Peng Z, Huang C, Tang H, Jia Z, Cui J, Le X, Huang S and Xie K: The critical role of dysregulated FOXM1-PLAUR signaling in human colon cancer progression and metastasis. Clin Cancer Res 19: 62-72, 2013.

38. Ahmad A, Ali S, Wang Z, Ali AS, Sethi S, Sakr WA, Raz A and Rahman KM: 3,3'-Diindolylmethane enhances taxotere-induced growth inhibition of breast cancer cells through downregulation of FoxM1. Int J Cancer 129: 1781-1791, 2011.

39. Ahmad A, Sakr WA and Rahman KM: Novel targets for detection of cancer and their modulation by chemopreventive natural compounds. Front Biosci 4: 410-425, 2012.

40. Ahmad A, Ali S, Ahmed A, Ali AS, Raz A, Sakr WA and Rahman KM: 3, 3'-Diindolylmethane enhances the effectiveness of herceptin against HER-2/neu-expressing breast cancer cells. PLoS One 8: e54657, 2013.

41. Ahmad A, Wang Z, Kong D, Ali S, Li Y, Banerjee S, Ali R and Sarkar FH: FoxM1 down-regulation leads to inhibition of proliferation, migration and invasion of breast cancer cells through the modulation of extra-cellular matrix degrading factors. Breast Cancer Res Treat 122: 337-346, 2010. 